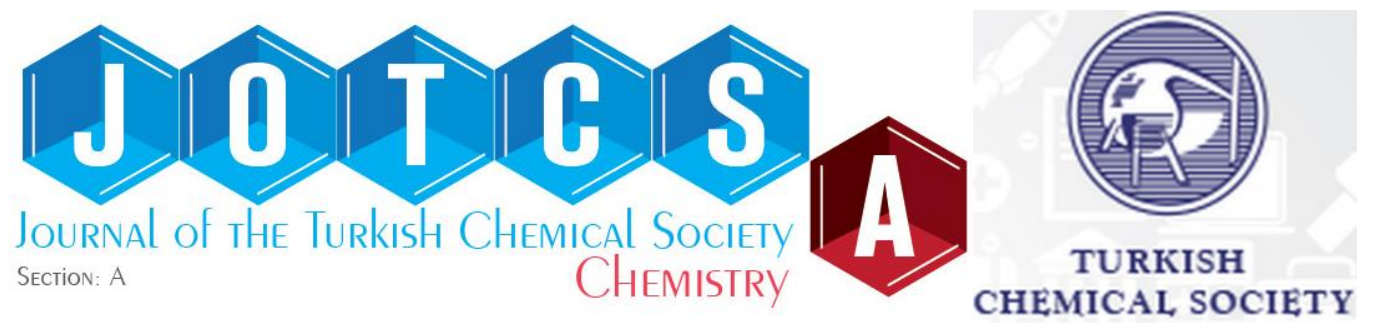

\title{
Synthesis and Characterization of Jeffamine Core PAMAM Dendrimer- Silver Nanocomposites (Ag JCPDNCs) and Their Evaluation in the Reduction of 4-Nitrophenol
}

\author{
Mustafa Ulvi Gürbüz ${ }^{1}$, Ali Serol Ertürk ${ }^{2 *}$ \\ ${ }^{1}$ Yıldız Technical University, Faculty of Arts and Sciences, Department of Chemistry, 34210, Esenler, \\ İstanbul, Turkey. \\ ${ }^{2}$ Adıyaman University, Faculty of Pharmacy, Department of Analytical Chemistry, 02040, Adıyaman, \\ Turkey.
}

Abstract: This paper presents the synthesis, characterization, and catalytic evaluation of Jeffamine core PAMAM dendrimer-silver nanocomposites (Ag JCPDNCs). Generation-4 polymeric Jeffamine cored PAMAM dendrimer (JCPD or P4. $\mathrm{NH}_{2}$ ) was used as the stabilizing and templating agent for the synthesis of AgJCPDNCs. Characterization of the synthesized Ag JCPDNC was performed by UV-visible (UV-Vis) spectroscopy and high resolution transmission electron microscopy (HRTEM). The catalytic activity of dendrimer nanocomposite (DNC) was assessed on the reduction of 4-nitrophenol (4-NP) to 4-aminophenol (4-AMP) in the presence of sodium borohydride $\left(\mathrm{NaBH}_{4}\right)$ as reducing agent by monitoring the conversion at $\lambda=400 \mathrm{~nm}$. The prepared Ag JCPDNCs displayed a good catalytic activity $\left(\mathrm{K}=0.12 \times 10^{-2} \mathrm{~s}^{-1}\right)$ for the model reduction reaction of 4-NP with the particle size distribution of $4.72 \pm 0.81 \mathrm{~nm}$, which offer a mixed type (interior and exterior) of DNC formation. The Ag JCPDNCs can be a valid complete alternative to their existing candidates in the literature with their different polymeric organics components and be great potential for the future studies as new materials.

Keywords: Poly (amidoamine) Dendrimers (PAMAMs), Dendrimer Nanocomposite (DNC), Jeffamine, 4nitrophenol, Kinetics.

Submitted: May 30, 2018. Accepted: July 16, 2018.

Cite this: Gürbüz M, Ertürk A. Synthesis and Characterization of Jeffamine Core PAMAM Dendrimer-Silver Nanocomposites (Ag JCPDNCs) and Their Evaluation in the Reduction of 4-Nitrophenol. JOTCSA. 2018;5(2):885-94.

DOI: http://dx.doi.org/10.18596/jotcsa.428572.

*Corresponding author. E-mail: aserturk@gmail.com; Phone: +90-416-2233800/2808; fax: +90 (416) 2233809.

\section{INTRODUCTION}

Over the last decades, due to their unique structural properties, metal nanoparticles (NPs) have received greater attraction in various applications compared to their bulk counterparts $(1,2)$. Although NPs have been applied in several applications (3-7), their use as catalysts has attracted great interest (8-10). In case of their prone-to-agglomerate in solution, stabilization of NPs is of great deal. Among various stabilizers such as surfactants (11), ligands, micelles and polymers $(12,13)$, dendrimers are promising templates to synthesize numerous transition metal NPs such as Ag (14-16), Au (14, 17), Cu $(18,19), \mathrm{Ni}(20)$, and Ru (21) with well-regulated size, position, and composition depending on their three-dimensional, monodisperse, unique architectures preventing them from nanoparticle growth, assembly, aggregation, and damage (22, 23). Thus, the size and shape of the resulting dendrimer nanocomposites (DNCs) or dendrimerencapsulated metal nanoparticles (DENs), can remain steady so that a constant desired activity can be reached. These characteristics of DNCs make them useful and attractive in various applications involving optoelectronics (24), semiconductor, noble metals, magnetic DNC, 
environmental cleanup, and especially in catalysis (25-27). In particular, DNCs can be potentially used in homogeneous and heterogeneous catalysis owing to their size and the ability to design catalytic active sites (28).

In recent years, DNCs have been intensively prepared and characterized by using commercially available ethylene diamine core poly(amido amine) (PAMAM) cored dendrimers, and their catalytic properties were investigated (22). Results of these studies revealed that generation number and surface functional group has a crucial role on effect on the catalytic activity of DNCs. However, no one to the best of our knowledge has studied to the preparation of DNCs by using a polymeric cored PAMAM dendrimer and a little attention has been paid for the preparation DNCs from PAMAMs having a different core than traditional ones (ethylene diamine) and investigation of their catalytic activities.

Nitrophenols are regarded to be one of the most common sources of organic pollutants from industrial and agricultural activities. This case also involves the companies which area manufacturing explosives, dyestuffs, insecticides, and other products (29-31). In particular, United States Environmental Protection Agency (USEPA) considers nitrophenols as the leading toxic pollutants (19). Interestingly, 4-aminophenol (4AMP) is an important commercial intermediate for the production of analgesic and antipyretic drugs, one of which is paracetamol (32). Thus, the direct catalytic reduction of 4-nitrophenol (4-NP) to the 4-AMP is a significant and urgent request by many industries as it could be an environmentally friendly process (33).

In one of our recent studies (34), we have reported the microwave assisted fast, facile and one pot synthesis of polymeric cored Jeffamine core PAMAM dendrimers (JCPDs) up to generation-4 (G4). Here, we introduce for the first time the synthesis and characterization of Jeffamine core PAMAM dendrimer-silver nanocomposites (Ag-JCPDNCs) with the use G4 JCPD and later applied these DNCs in the catalytic conversion of 4-NP to 4-AMP by using sodium borohydride $\left(\mathrm{NaBH}_{4}\right)$.

\section{MATERIALS AND METHODS}

\section{Chemicals and Materials}

Jeffamine ${ }^{\circledR}$ T-403 cored and amine terminated P4. $\mathrm{NH}_{2}$ PAMAM dendrimers were synthesized by using microwave technology according to the procedure which was reported in our recent study (34). All the other chemicals were of analytical grade and obtained from Merck and Sigma chemical companies, and used without any further purifications. All the experiments were conducted using ultrapure water $(18.2 \mathrm{~m} \Omega \mathrm{cm})$ from a Millipore Milli-Q system.

\section{Instrumentation}

$\mathrm{pH}$ measurements were performed with Mettler Toledo five easy $\mathrm{pH}$ meter. Calibration of the $\mathrm{pH}$ meter was performed by using $\mathrm{pH}$ solutions at $4.01,7.00$ and 10.01 standard solutions (Merck Millipore, USA).

Ultraviolet-visible (UV-Vis) absorption spectra were recorded with Cary 60 UV-Vis spectrophotometer (Agilent, USA) with $1-\mathrm{cm}$ quartz cells. The morphology and the sizes of the Ag JCDNCs were characterized using a Tecnai G2 Spirit BioTwin high resolution transmission electron microscope (HRTEM, FEI, USA) at $80 \mathrm{kV}$ accelerating voltage. The microscope was equipped with a charge couple device (CCD) digital camera and samples were prepared by using 200 mesh carbon-coated copper grid.

Microwave-irradiated reactions were carried out with a microwave reactor (Discover SP, CEM, Matthews, NC, USA), with a continuous microwave power delivery system with operator selectable power output from 0 to $300 \mathrm{~W}$ ( $\pm 30 \mathrm{~W}$ ) programmable at 1-watt increments, infrared temperature control system programmable from 25 to $250^{\circ} \mathrm{C}$, pressure controlled and 5 to $125 \mathrm{~mL}$ vessel capacity was used as microwave reactor.

\section{Preparation of Ag-JCPDNCs}

The synthetic method used in the preparation of Ag JCPDNCs was adapted from the literature with slight modifications (35). Briefly, the $\mathrm{pH}$ of the P4. $\mathrm{NH}_{2} 2 \mathrm{mM}$ dendrimer solution $(0.2 \mathrm{mmol}, 10$ $\mathrm{mL}$ in water) was adjusted approximately to 2.0 by using $0.1 \mathrm{~N} \mathrm{HNO}_{3}$ solution. Then, aqueous 8 . $75 \mathrm{mM} \mathrm{AgNO}_{3}$ solution ( $2 \mathrm{mmol}, 228 \mu \mathrm{L}$ ) was added to the dendrimer solution. The mixture was stirred for $4 \mathrm{~h}$ by purging nitrogen to allow $\mathrm{Ag}^{+}$ ions to coordinate with the tertiary amine groups of the dendrimer. This was followed by the dropwise addition of 10 -fold excess of $0.1 \mathrm{M}$ $\mathrm{NaBH}_{4}$ aqueous solution ( $20 \mathrm{mmol}, 200 \mu \mathrm{L}$ ) to reduce the $\mathrm{Ag}^{+}$ions to $\mathrm{Ag}^{0}$ in $\mathrm{P} 4 . \mathrm{NH}_{2} / \mathrm{Ag}^{+}$salt complex. The colorless solutions turned immediately to yellow. The reaction was stirred for $1 \mathrm{~h}$ at room temperature and the UV-Vis measurements were performed (Scheme 1). 

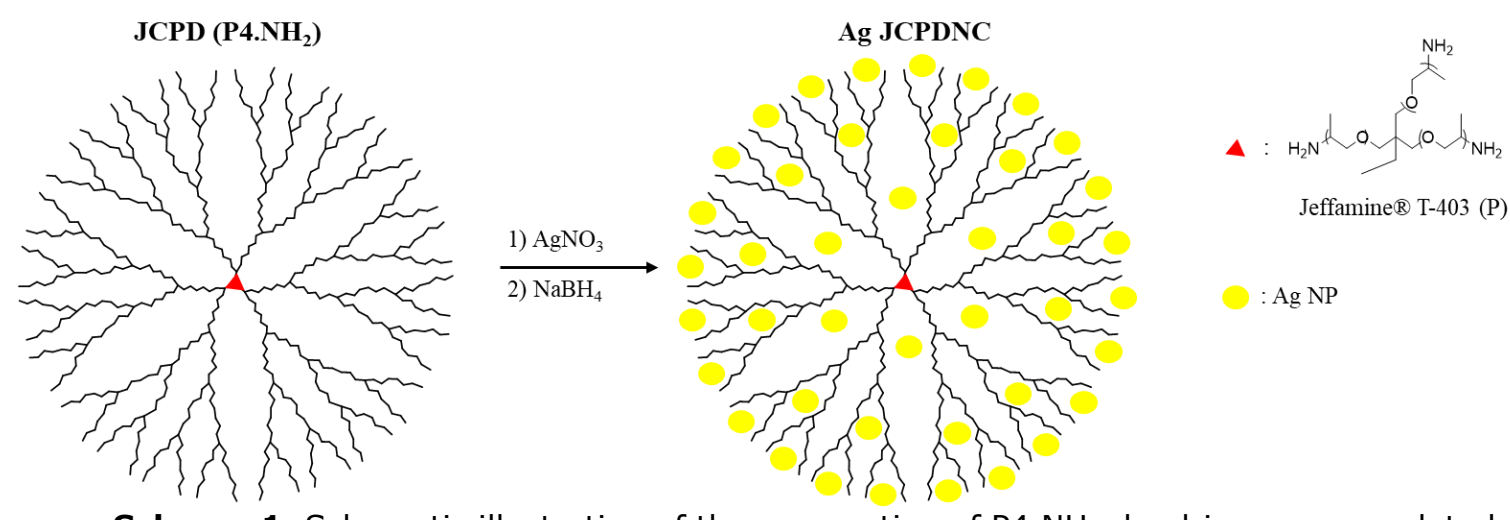

Scheme 1. Schematic illustration of the preparation of $\mathrm{P} 4 . \mathrm{NH}_{2}$ dendrimer-encapsulated silver nanoparticles (Ag JCPDNCs).

\section{Catalytic Activity Assay}

The catalytic activity of Ag JCPDNCs was investigated in the reduction of 4-NP to 4-AMP. In a typical catalysis assay, Ag JCPDNC (100 $\mu \mathrm{L}$, $0.02 \mathrm{mM}), 0.1 \mathrm{M} \mathrm{NaBH}_{4}(35 \mathrm{mmol}, 350 \mu \mathrm{L})$, deionized water $(2.5 \mathrm{~mL})$ and $12.75 \mathrm{mM} \mathrm{4-NP}(0.38$ $\mathrm{mmol}, 30 \mu \mathrm{L}$ ) were mixed together in a $10 \mathrm{~mm}$ path-length glass cuvette. The change in the absorbance of 4-NP as a function of time was monitored by UV-Vis spectrophotometry in the wavelength range of 250-500 nm immediately. The yellow solution turned to colorless gradually in the presence of dendrimer nanocomposites.

\section{RESULTS AND DISCUSSION}

\section{Characterization of Ag JCPDNCs}

The preparation of $\mathrm{Ag}$ JCPDNCs using JCPDs as templates were monitored by UV-Vis spectra (Figure 1). Investigation of Figure 1 showed that neat aqueous JCPD solution displayed an absorption band approximately at $\lambda 284 \mathrm{~nm}$ in accordance well correlated with the literature (34). The sudden appearance of a new absorption band at around $\lambda 300 \mathrm{~nm}$, indicating the occurrence of $\left(\mathrm{Ag}^{+}\right)_{10}$ JCPD complex between the tertiary amine groups of PAMAMs and $\mathrm{Ag}^{+}$ions (36), was seen by the addition of the $\mathrm{AgNO}_{3}$ solution. After reduction by $\mathrm{NaBH}_{4}$, an intense plasmon peak at $\lambda 400 \mathrm{~nm}$ were formed. This clear UV-Vis band was the proof the formation of Ag JCPDNCs and all these spectral changes were in good alignment with the literature where PAMAMs are used as templates for Ag NP preparation $(35,37,38)$.

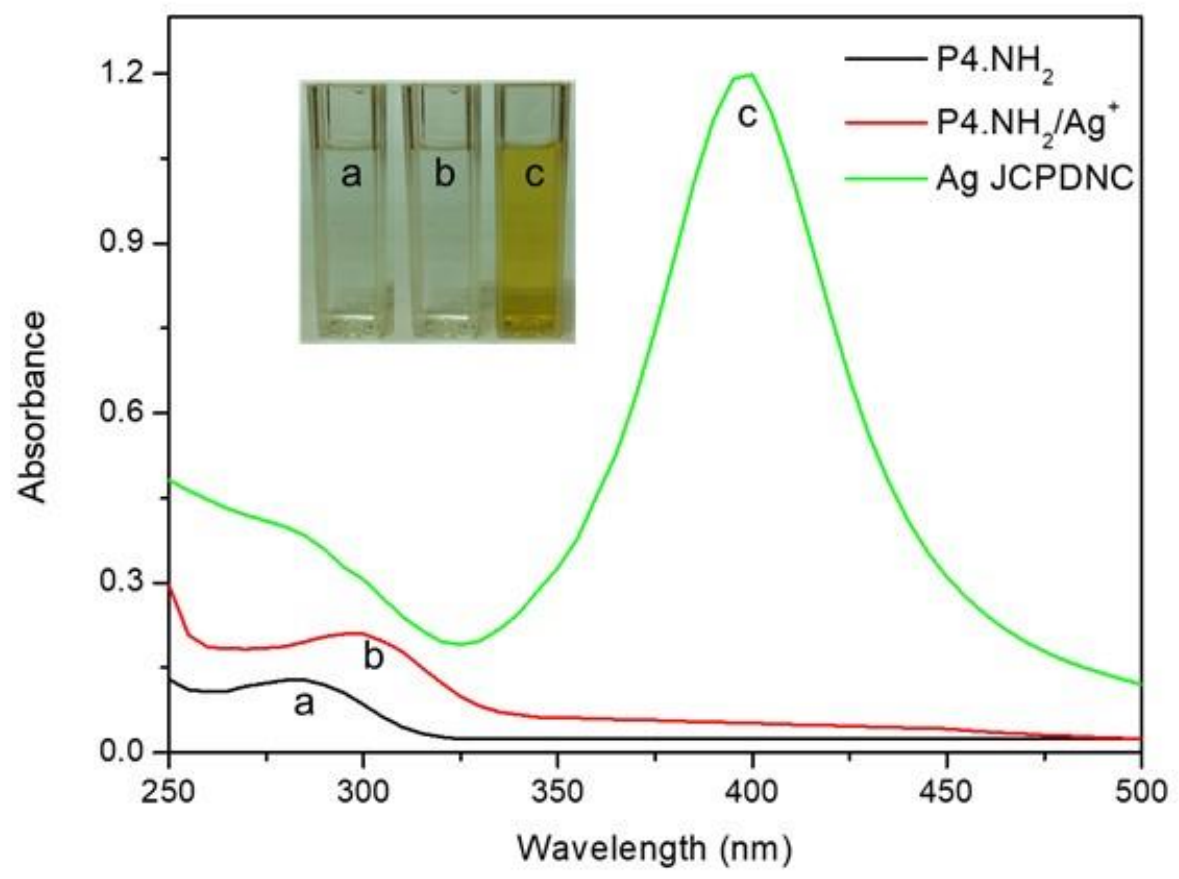

Figure 1. UV-Vis spectra of (a) JCPD or P4. $\mathrm{NH}_{2}$, aqueous solution, (b) $\mathrm{P} 4 . \mathrm{NH}_{2} / \mathrm{Ag}^{+}$complex and (c) $\mathrm{Ag}$ JCPDNC.

Unlike conventional NPs, which are usually in the structure of microcrystalline and their surface are passivated against further crystallization leading to secondary clustering by stabilizers, DNCs are soft hybrid materials composed of inorganic domains embedded inside or dispersed on the surface of dendrimers and covalent branches behaving like separators (39). Such kind of their 
unique structures enable them to be often as amorphous in different types of single nanocomposite structures in which the metal NPs are generated or stabilized as internal "I" (intra type DENs), external "E" (inter type DENs) or mixed "M". Former studies revealed that metallodendrimers, having average particle size between 1 to $4 \mathrm{~nm}$, are supposed to be intra type DENs while those of greater than $5 \mathrm{~nm}$ are called as inter type DENs $(39,40)$.

In order to provoke the small sized Ag NP formation, we have kept the $\mathrm{pH} 2$ and the time long by keeping to metal to dendrimer ratio (10) almost approximate the one fifth of the tertiary amine number (45) of JCPD P4. $\mathrm{NH}_{2}$ so as to promote the formation of interior type DNCs. The morphology and the average NP size distribution were analyzed using HRTEM. The resultant micrograph and particle size distribution histogram are shown in Figure 2. In general, the

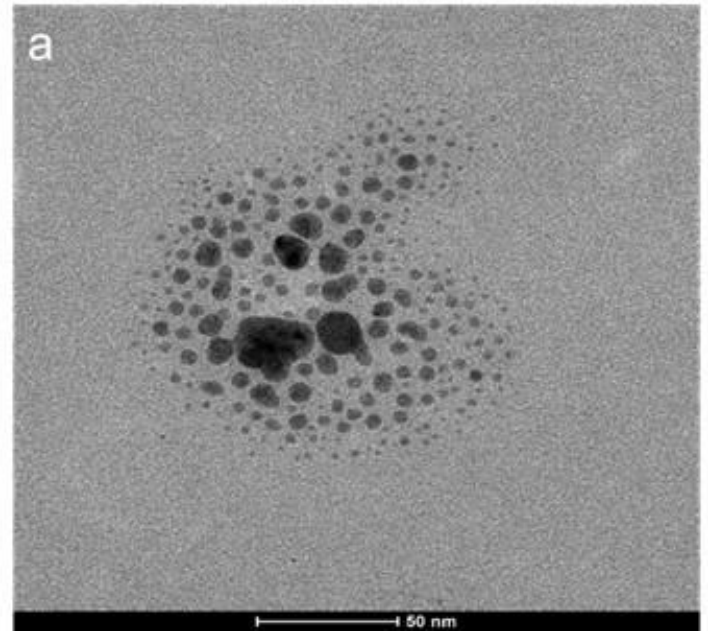

Figure 2. HRTEM image (a) and particle size distribution histogram of Ag JCPDNC (b).

\section{Catalytic activity and UV measurements}

The model reduction reaction of 4-NP to 4-AMP with $\mathrm{NaBH}_{4}$ as the hydrogen source was chosen to estimate the catalytic activity of the synthesized Ag-JCPDNCs (35). This reaction has a unique feature of exhibiting maximum absorbance band at $\lambda 317 \mathrm{~nm}$ in water whereas it has a maximum at $\lambda 400 \mathrm{~nm}$ because of its conversion to $p$-nitrophenolate and can be pursued easily by observing the alteration in the UV-Vis spectrum at $\lambda 300$ and $400 \mathrm{~nm}$ (41). Before investigating the catalytic activity of DNCs, $\mathrm{NaBH}_{4}$ was added to the 4-NP solution without the nanocatalyst to prove that the $\mathrm{NaBH}_{4}$ compound used during the reduction only as the proton source. After $24 \mathrm{~h}$, UV-Vis measurement of the prepared solution was taken again and an insignificant decrease in the adsorption band of 4$\mathrm{NP}$, which is indicating a non-proceeding of the reduction reaction even with the use of large

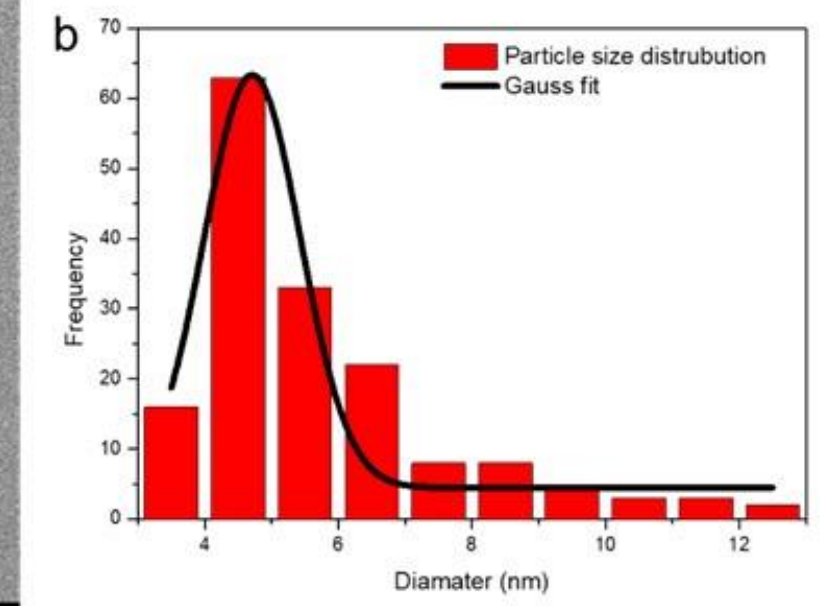

shape of $\mathrm{Ag}$ DENs exhibited spherical morphology. HRTEM characterization showed $83.06 \%$ distribution with the Ag DEN size of 4.71 $\pm 0.845 \mathrm{~nm}$. It is noteworthy that the $\mathrm{Ag}$ DENs with the polydispersity index of $17.94 \%$. These HRTEM results indicated and it could be concluded that mixed " $M$ " type DNCs, where the NPs are stabilized in both interior and exterior of dendrimer, were formed in all cases when the JCPDs are used as the templating agent for the preparation of DNCs since the average NP size obtained in this study were above $4 \mathrm{~nm}$ but not greater than $5 \mathrm{~nm}(39,40)$. Indeed, the smallest Ag DEN can be reasonably attributed to "I" type nanocomposite formation while biggest particles can be evidenced to " $E$ " type formations. This could be attributed to use of G4 JCPD as the templating agent for the preparation of Ag DENs as being different from the existing literature where the conventional ethylene diamine monomer used as the core $(35,37,38)$.

amount of $\mathrm{NaBH}_{4}$, was remarked (Figure 3). In the presence of a catalyst, the addition of $\mathrm{NaBH}_{4}$ arose a gradual drop in the absorption band $\lambda 400$ $\mathrm{nm}$ while a new characteristic absorption band occurrence and increase at around $295 \mathrm{~nm}$, which is the characteristic peak of 4-AMP and signal of the successful reduction of the 4-NP to 4-AMP, was observed. $(42,43)$ (Figure 4). It is noteworthy that the UV-Vis spectra are useful tools to identify the species in the solution; however, it fails while getting information about the intermediated on the particle surfaces. All in all, the isosbestic point at $\lambda \sim 325 \mathrm{~nm}$ proves the complete transformation of 4-NP to 4-AMP without side reactions (44). Therefore, it could be inferred that the reactant molecules establish a direct contact with the Ag DENs by transferring electrons from the donor $\mathrm{BH}_{4}{ }^{-}$to the acceptor 4NP by adsorption through the dendrimer nanocomposites (42). 


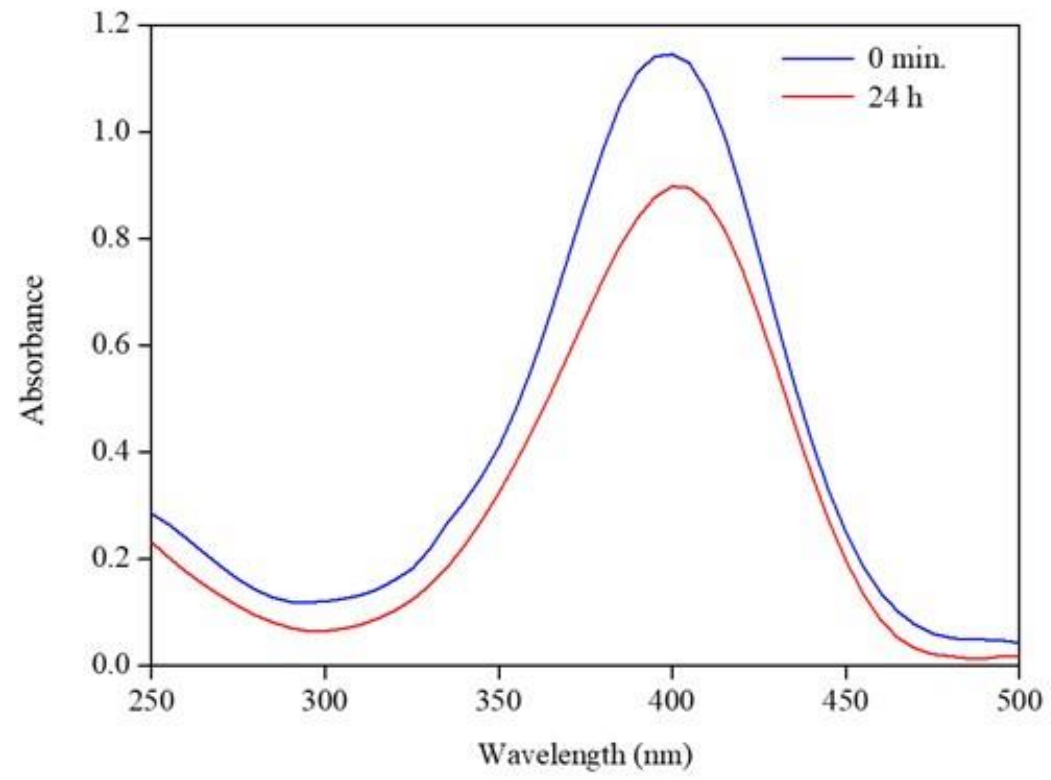

Figure 3. UV-Vis spectra of 4-NP in the presence of $\mathrm{NaBH}_{4}$ without Ag JCPDNC.

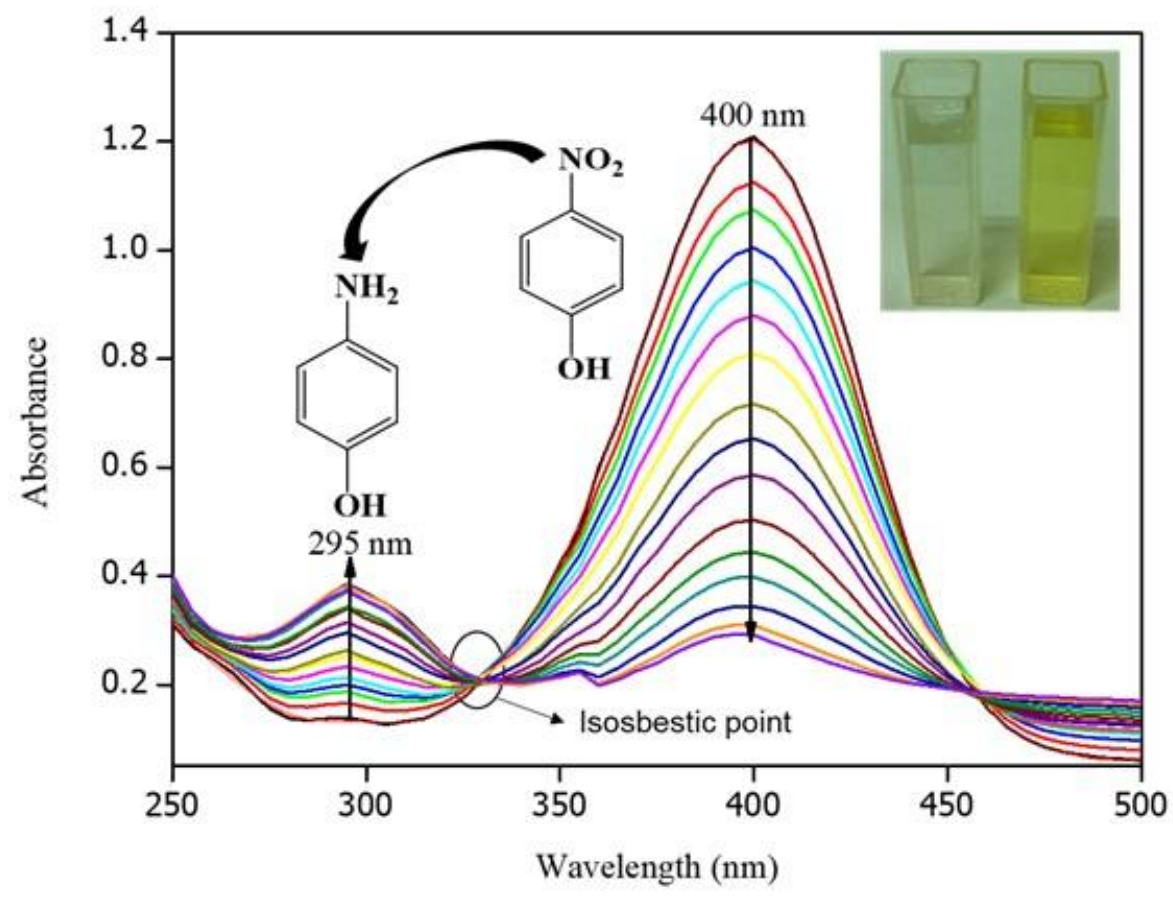

Figure 4. Time based variation in the UV-Vis spectra for the 4-NP reduction reaction in the presence of Ag JCPDNC $\left([4-\mathrm{NP}]=0.38 \mathrm{mmol} ;\left[\mathrm{NaBH}_{4}\right]=35 \mathrm{mmol} ;[\mathrm{Ag} J \mathrm{CPDNC}]=0.02 \mathrm{mM} ; 25^{\circ} \mathrm{C}\right)$

In the reduction experiments, the reaction media was purged with nitrogen to avoid oxygen. Nevertheless, an induction time was observed in all cases up to $200 \mathrm{sec}$ (Figure 5). This case is a typical one and is related with the activation time of the catalyst at heterogeneous catalytic processes (41). As the concentration of the all used $\mathrm{NaBH}_{4}$ was in considerable excess in contrast to 4-NP, the reduction process guarantees pseudo-first-order reaction conditions as demonstrated in Figure 5. Investigation of Figure 5 reveals that there occurs and intercept point at the absorbance variation scatter plots at $\lambda 295$ and $400 \mathrm{~nm}$ bands in time. This is the point where the solution color decolorized from yellow to colorless and the reaction ended (776.47 sec). The inset of Figure 5 displays the first order kinetic plots for the Ag JCPNCs. As it can be seen clearly, the linear fitting plot of $\ln \left(A / A_{0}\right)$ versus time obeys the first order kinetics and the apparent first-order rate constant (K) were calculated as $0.0012 \mathrm{~s}^{-1}$ from the slope of this curve $\left(R^{2}=0.9982\right)$. 


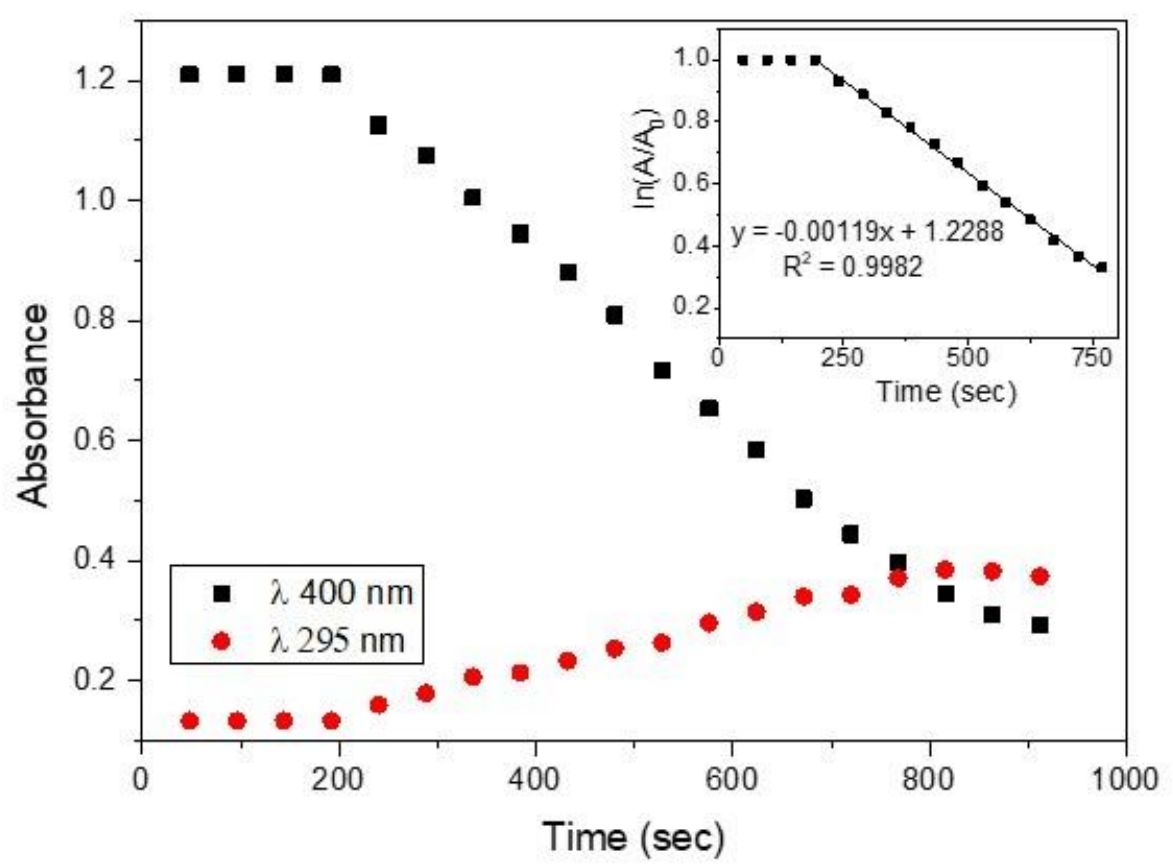

Figure 5. Time dependence of the adsorption of 4-NP ions at $\lambda 295$ and $400 \mathrm{~nm}$. The inset demonstrates the linear fit for the first order kinetics at $\lambda 400 \mathrm{~nm}\left([4-\mathrm{NP}]=0.38 \mathrm{mmol} ;\left[\mathrm{NaBH}_{4}\right]=35 \mathrm{mmol} ;[\mathrm{Ag}\right.$ JCPDNC] $\left.=0.02 \mathrm{mM} ; 25^{\circ} \mathrm{C}\right)$

Table 1 shows the catalytic results obtained from different works for the reduction of 4-NP in the presence of Ag DNCs with different structures, where the Ag DENs involved and prepared by ethylene diamine cored conventional G4 amineterminated PAMAMs as templates $(15,16,35)$. As can be seen from Table 1 , the rate constant obtained here for Ag JCPDNCs was considerable higher than DNCs having possible exterior type DNC structure while approximate to ones with interior type DNC structures. Notably, it could be clearly seen from Table 1 that a small decrease in the size of $\mathrm{Ag}$ DENs are resulted in observable enhance at the rate constant. This could be attributed to size and shape dependence of the synthesized Ag DENs to the type and variation of architecture of the used dendrimer template in the aqueous media as well as the synthesis conditions. Several factors such as generation size, type of core and repeating branches, density of functional groups and voids in the inner cavities can affect the conformation of dendrimers in aqueous media (45). Among these factors, $\mathrm{pH}$ is the one of the most important factors. Previous studies have shown that upon lowering the $\mathrm{pH}$, amine-terminated PAMAMs display extended configuration owing to the electrostatic repulsions stemming from the protonated tertiary amine groups in the interior and primary amine groups at the periphery so that dendrimer branches apart $(46,47)$. On the contrary, at high pHs over 9, shrinking or back-folding happens on account of the hydrogen bonding between the tertiary amine and surface primary amine groups leading a densely packed structure to dendrimer $(47,48)$. Considering these results, the common property of the procedures presented in Table 1 except for exterior type possible DNC structure formation is the use of acidic media, $\mathrm{pH} \sim 2$, in the preparation of Ag DENs with a well-defined metal dendrimer ratio for G4 amine-terminated PAMAMs. Thus, the extended structure of the dendrimer templates should be favored to formation of inner type DENs with particles sizes lower than $4 \mathrm{~nm}$. For our study, mixed type DNC structure have been observed. This could be attributed to $\mathrm{pH}$ dependent conformational change and nature of the charged groups on the polymeric Jeffamine core $\mathrm{P} 4 . \mathrm{NH}_{2}$ PAMAM template due to their extent of protonation, and therefore, stabilization properties while preparing Ag DNCs. In particular, it might be difficult for the substrate to contact the active metallic site on Ag JCPDNCs due to its different $\mathrm{pH}$ dependent conformation that may lead to increase in sterically branches emanating from three arms in contrast to two for conventional PAMAMs. Thus, this could be also attributed differences in particle sizes and negligible catalytic activity decrease for $\mathrm{Ag}$ JCPDNCs. Overall, the proposed Ag JCPDNCs in here can be complete and good alternative to other Ag DENs present in the literature with mixed type possible structures and good catalytic behaviors. 
Table 1. Comparison of the rate constants of Ag DNCs with the literature.

\begin{tabular}{llllll}
\hline Catalyst & $\begin{array}{l}\text { Dendrimer } \\
\text { core }\end{array}$ & $\begin{array}{l}\text { Possible DNC } \\
\text { structure }\end{array}$ & $\mathbf{D} \mathbf{( n m )}$ & $\mathbf{K}\left(\mathbf{s}^{\mathbf{- 1}}\right)$ & Reference \\
\hline $\mathrm{Ag}_{12} \mathrm{DEN}$ & $\mathrm{EDA}$ & Interior & $3.1 \pm 0.6$ & $0.7 \times 10^{-2}$ & $(35)$ \\
$\mathrm{Ag}_{13} \mathrm{DEN}$ & $\mathrm{EDA}^{\mathrm{a}}$ & Interior & $1.17 \pm 0.13$ & $1.1 \times 10^{-2}$ & $(15)$ \\
$\mathrm{Ag}$ DEN & EDA & Exterior & $6.5 \pm 1.9$ & $5.9 \times 10^{-4}$ & $(16)$ \\
$\mathrm{Ag}_{10} \mathrm{DEN}$ & Jeffamine & Mixed & $4.72 \pm 0.81$ & $0.12 \times 10^{-2}$ & This work \\
\hline
\end{tabular}

a EDA: Ethylene diamine

b Mixed: Interior and exterior

\section{CONCLUSIONS}

In this paper, G4 JCPDs which has a polymeric Jeffamine core were evaluated for the first time for the preparation of Ag JCPDNCs. The average particle size was found to be $4.72 \pm 0.81 \mathrm{~nm}$, which offers a mixed type of possible DNC structure. The prepared Ag JCPDNCs were found as catalytically active in the model reduction of 4NP to 4-AMP by demonstrating first-order kinetics with a rate constant of $0.12 \times 10^{-2} \mathrm{~s}^{-1}$, which offers a satisfactory and pleasurable performance compared with the existing literature with its different size distributions and structures. In particular, the synthesized Ag JCPDNCs can be a valid complete alternative and great potential to their existing candidates in the literature with their different polymeric organics components for the future studies.

\section{ACKNOWLEDGMENT}

This research has been supported by Adıyaman University Scientific Research Projects Coordination Department. Project Number: MÜFMAP/2015-0004.

\section{REFERENCES}

1. Daniel MC, Astruc D. Gold Nanoparticles: Assembly, Supramolecular Chemistry, QuantumSize-Related Properties, and Applications Toward Biology, Catalysis, and Nanotechnology. Chem Rev. 2004;104(1):293-346.

2. Lkhagvajav N, Yaşa I, Çelik E, Koizhaiganova M, Sari O. Antimicrobial activity of colloidal silver nanoparticles prepared by sol-gel method. Dig J Nanomat Biostr. 2011;6(1):149-54.

3. Ertürk AS, Elmacl G. PAMAM Dendrimer Functionalized Manganese Ferrite Magnetic Nanoparticles: Microwave-Assisted Synthesis and Characterization. J Inorg Organomet Polym Mater. 2018.

4. Colvin VL, Schlamp MC, Alivisatos AP. Lightemitting diodes made from cadmium selenide nanocrystals and a semiconducting polymer. Nature. 1994;370(6488):354-7.

5. Elghanian R, Storhoff JJ, Mucic RC, Letsinger $\mathrm{RL}$, Mirkin CA. Selective colorimetric detection of polynucleotides based on the distancedependent optical properties of gold nanoparticles. Science. 1997;277(5329):107881.

6. Reetz MT, Winter M. Fabrication of metallic and bimetallic nanostructures by electron beam induced metallization of surfactant stabilized Pd and Pd/Pt clusters. J Am Chem Soc. 1997;119(19):4539-40.

7. Schön G, Simon U. A fascinating new field in colloid science: small ligand-stabilized metal clusters and their possible application in microelectronics - Part II: Future directions. Colloid Polym Sci. 1995;273(3):202-18.

8. Chen HC, Liu YC. Creating functional water by treating excited gold nanoparticles for the applications of green chemistry, energy and medicine: A review. J Ind Eng Chem. 2018;60:9-18.

9. Patnaik S, Sahoo DP, Parida K. An overview on Ag modified g-C3N4 based nanostructured materials for energy and environmental applications. Renewable Sustainable Energy Rev. 2018;82:1297-312.

10. Xiao W, Lei W, Gong M, Xin HL, Wang D. Recent Advances of Structurally Ordered Intermetallic Nanoparticles for Electrocatalysis. ACS Catal. 2018;8(4):3237-56.

11. Goikolea E, Insausti M, Lezama L, Gil de Muro I, Garitaonandia JS. Magnetic and structural characterization of silver-iron oxide nanoparticles obtained by the microemulsion technique. J Non-Cryst Solids. 2008;354(4751):5216-8.

12. Manesh KM, Gopalan AI, Lee KP, Komathi S. Silver nanoparticles distributed into polyaniline bridged silica network: A functional nanocatalyst having synergistic influence for catalysis. Catal Commun. 2010;11(10):913-8.

13. Harish S, Mathiyarasu J, Phani KLN, Yegnaraman V. Synthesis of conducting polymer supported Pd nanoparticles in aqueous medium and catalytic activity towards 4-nitrophenol reduction. Catal Lett. 2009;128(1-2):197-202.

14. Nemanashi M, Meijboom R. Synthesis and characterization of $\mathrm{Cu}, \mathrm{Ag}$ and $\mathrm{Au}$ dendrimerencapsulated nanoparticles and their application in the reduction of 4-nitrophenol to 4- 
aminophenol. J Colloid Interface Sci. 2013;389(1):260-7.

15. Bingwa N, Meijboom R. Evaluation of catalytic activity of $\mathrm{Ag}$ and $\mathrm{Au}$ dendrimerencapsulated nanoparticles in the reduction of 4nitrophenol. J Mol Catal A: Chem. 2015;396:1-7.

16. Esumi K, Isono R, Yoshimura T. Preparation of PAMAM- and PPI-Metal (Silver, Platinum, and Palladium) Nanocomposites and Their Catalytic Activities for Reduction of 4Nitrophenol. Langmuir. 2004;20(1):237-43.

17. Wu H, Liu Z, Wang X, Zhao B, Zhang J, Li C. Preparation of hollow capsule-stabilized gold nanoparticles through the encapsulation of the dendrimer. $]$ Colloid Interface Sci. 2006;302(1):142-8.

18. Ertürk AS, Gürbüz MU, Tülü $M$, Bozdoğan AE. Preparation of $\mathrm{Cu}$ nanocomposites from EDA, DETA, and Jeffamine cored PAMAM dendrimers with TRIS and carboxyl surface functional groups. Acta Chim Slov. 2016;63(4):763-71.

19. Feng ZV, Lyon JL, Croley JS, Crooks RM, Vanden Bout DA, Stevenson KJ. Synthesis and Catalytic Evaluation of Dendrimer-Encapsulated Cu Nanoparticles. An Undergraduate Experiment Exploring Catalytic Nanomaterials. J Chem Educ. 2009;86(3):368.

20. Ma Z, Wu R, Han Q, Chen R, Gu Z. Preparation of well-dispersed and anti-oxidized Ni nanoparticles using polyamioloamine dendrimers as templates and their catalytic activity in the hydrogenation of p-nitrophenol to p-aminophenol. Korean J Chem Eng. 2011;28(3):717-22.

21. Antonels NC, Meijboom R. Preparation of well-defined dendrimer encapsulated ruthenium nanoparticles and their evaluation in the reduction of 4-nitrophenol according to the langmuir-hinshelwood approach. Langmuir. 2013;29(44):13433-42.

22. Tang YH, Huang AYT, Chen PY, Chen HT, Kao CL. Metallodendrimers and dendrimer nanocomposites. Catal Commun. 2011;17(22):2308-30.

23. Lesniak W, Blelinska AU, Sun K, Janczak KW, Shi X, Baker Jr JR, et al. Silver/dendrimer nanocomposites as biomarkers: Fabrication, characterization, in vitro toxicity, and intracellular detection. Nano Lett. 2005;5(11):2123-30.

24. Alivisatos AP. Semiconductor Clusters, Nanocrystals, and Quantum Dots. Science. 1996;271(5251):933-7.
25. Knapen JWJ, van dMAW, de WJC, van LPWNM, Wijkens P, Grove DM, et al. Homogeneous catalysts based on silane dendrimers functionalized with arylnickel(II) complexes. Nature 1994;372(6507):659-63.

26. Tomalia DA, Dvornic PR. What promise for dendrimers? Nature. 1994;372(6507):617-8.

27. Balogh L, Tomalia DA. Poly(Amidoamine) Dendrimer-Templated Nanocomposites. 1. Synthesis of Zerovalent Copper Nanoclusters. J Am Chem Soc. 1998;120(29):7355-6.

28. Van HR, Kamer PCJ, Van LPWNM, Reek JNH. Dendrimers as Support for Recoverable Catalysts and Reagents. Chem Rev 2002;102(10):3717-56.

29. Iinuma $Y$, Brueggemann E, Gnauk T, Mueller K, Andreae MO, Helas G, et al. Source characterization of biomass burning particles: the combustion of selected European conifers, African hardwood, savanna grass, and German and Indonesian peat. J Geophys Res. 2007;112(D8):D08209/1-D/26.

30. Mori T, Watanuki T, Kashiwagura T. Diesel exhaust particles disturb gene expression in mouse testis. Environ Toxicol. 2007;22(1):5863.

31. Li C, Taneda S, Suzuki AK, Furuta C, Watanabe G, Taya K. Estrogenic and antiandrogenic activities of 4-nitrophenol in diesel exhaust particles. Toxicol Appl Pharmacol. 2006;217(1):1-6.

32. Rode CV, Vaidya MJ, Jaganathan R, Chaudhari RV. Hydrogenation of nitrobenzene to p-aminophenol in a four-phase reactor: Reaction kinetics and mass transfer effects. Chem Eng Sci. $2001 ; 56(4): 1299-304$.

33. Chen R, Wang Q, Du Y, Xing W, Xu N. Effect of initial solution apparent $\mathrm{pH}$ on nano-sized nickel catalysts in $\mathrm{p}$-nitrophenol hydrogenation. Chem Eng J. 2009;145(3):371-6.

34. Ertürk AS, Tülü $M$, Bozdoğan AE, Parali $T$. Microwave assisted synthesis of Jeffamine cored PAMAM dendrimers. Eur Polym J. 2014;52:218-26.

35. Nemanashi M, Meijboom R. Synthesis and characterization of $\mathrm{Cu}, \mathrm{Ag}$ and $\mathrm{Au}$ dendrimerencapsulated nanoparticles and their application in the reduction of 4-nitrophenol to 4aminophenol. Journal of Colloid and Interface Science. 2013;389(1):260-7.

36. Subhas G, Sangeeta Y, Nadarajah V, Gabriela S. A study of antimicrobial property of textile fabric treated with modified dendrimers. J Appl Polym Sci. 2010;115(2):716-22. 
37. Manna A, Imae T, Aoi K, Okada M, Yogo T. Synthesis of dendrimer-passivated noble metal nanoparticles in a polar medium: Comparison of size between silver and gold particles. Chem Mater. 2001;13(5):1674-81.

38. Esumi K, Suzuki A, Yamahira A, Torigoe K. Role of poly (amidoamine) dendrimers for preparing nanoparticles of gold, platinum, and silver. Langmuir. 2000;16(6):2604-8.

39. Balogh L, Valluzzi R, Laverdure KS, Gido SP, Hagnauer GL, Tomalia DA. Formation of Silver and Gold Dendrimer Nanocomposites. J Nanopart Res. 1999;1(3):353-68.

40. Manniledam K, R. PM, Edamana P, C. V, C. DP. Generation of Ag Nanoparticles by PAMAM Dendrimers and their Size Dependence on the Aggregation Behavior of Dendrimers. Macromol Chem Phys. 2009;210(16):1310-8.

41. Santos KdO, Elias WC, Signori AM, Giacomelli FC, Yang H, Domingos JB. Synthesis and Catalytic Properties of Silver Nanoparticle-
Linear Polyethylene Imine Colloidal Systems. J Phys Chem C. 2012;116(7):4594-604.

42. Kurtan U, Baykal A. Fabrication and characterization of Fe304@APTES@PAMAM-Ag highly active and recyclable magnetic nanocatalyst: Catalytic reduction of 4 nitrophenol. Mater Res Bull. 2014;60:79-87.

43. Pradhan N, Pal A, Pal T. Catalytic reduction of aromatic nitro compounds by coinage metal nanoparticles. Langmuir. 2001;17(5):1800-2.

44. Corma A, Concepción P, Serna P. A different reaction pathway for the reduction of aromatic nitro compounds on gold catalysts. Angew Chem. 2007;46(38):7266-9.

45. Martinho N, Florindo $H$, Silva L, Brocchini $S$, Zloh M, Barata T. Molecular Modeling to Study Dendrimers for Biomedical Applications. Molecules (Basel, Switzerland). 2014;19(12):20424-67.

46. Lee I, Athey BD, Wetzel AW, Meixner W, Baker Jr JR. Structural molecular dynamics studies on polyamidoamine dendrimers for a therapeutic application: Effects of $\mathrm{pH}$ and generation. Macromolecules. 2002;35(11):451020. 
47. Maiti PK, Çağın T, Lin S-T, Goddard WA.

Effect of Solvent and $\mathrm{pH}$ on the Structure of

PAMAM Dendrimers. Macromolecules.

2005;38(3):979-91.

48. Chen W, Tomalia DA, Thomas JL. Unusual $\mathrm{pH}$-dependent polarity changes in PAMAM dendrimers: evidence for $\mathrm{pH}$-responsive conformational changes. Macromolecules. 2000;33(25):9169-72. 
